REVIEW

\title{
Gastro-oesophageal reflux monitoring: review and consensus report on detection and definitions of acid, non-acid, and gas reflux
}

\author{
D Sifrim, D Castell, J Dent, P J Kahrilas
}

Gut 2004;53:1024-1031. doi: 10.1136/gut.2003.033290

To date, most concepts on the frequency of gastrooesophageal reflux episodes and the efficiency of the antireflux barrier have been based on inferences derived from measurement of oesophageal $\mathrm{pH}$. The development of intraluminal impedance monitoring has highlighted the fact that $\mathrm{pH}$ monitoring does not detect all gastro-oesophageal reflux events when little or no acid is present in the refluxate, even if special $\mathrm{pH}$ tracing analysis criteria are used. In November 2002, a workshop took place at which 11 specialists in the field of gastro-oesophageal reflux disease discussed and criticised all currently available techniques for measurement of reflux. Here, a summary of their conclusions and recommendations of how to achieve the best results from the various techniques now available for reflux measurement is presented.

See end of article for authors' affiliations

Correspondence to Dr D Sifrim, Faculty of Medicine, Lab Gastrointestinal Fysiopathology, O\&N Gasthuisberg, 7th Floor, Herestraat 49, 3000 Leuven, Belgium; daniel.sifrim@ med.kuleuven.ac.be

Accepted for publication 3 February 2004

\section{SUMMARY}

To date, most concepts on the frequency of gastro-oesophageal reflux episodes and the efficiency of the antireflux barrier have been based on inferences derived from measurement of oesophageal pH. The development of intraluminal impedance monitoring has highlighted the fact that $\mathrm{pH}$ monitoring does not detect all gastro-oesophageal reflux events when little or no acid is present in the refluxate, even if special $\mathrm{pH}$ tracing analysis criteria are used. The total rate of reflux episodes is an important indicator of the competence of the antireflux barrier and is therefore relevant when evaluating the effect of therapies directed at improving antireflux barrier function. In November 2002, a workshop took place at which 11 specialists in the field of gastro-oesophageal reflux disease (see list of contributors at the end of this article) discussed and criticised all currently available techniques for measurement of reflux. This paper presents a synthesis of their conclusions and recommendations of how to achieve the best results from the various techniques now available for reflux measurement.

It was concluded that intraluminal impedance monitoring is the only recording method that can achieve high sensitivity for detection of all types of reflux episodes while pH-metry is required for characterisation of reflux acidity. However, the

role of intraluminal impedance in the management of patients with gastro-oesophageal reflux disease still needs to be defined from appropriately designed clinical trials.

The impact of new techniques on the definition of different types of reflux was also discussed extensively at the workshop, and new or slightly amended definitions are proposednamely, "acid reflux", "superimposed acid reflux", "weakly acidic reflux", and "weakly alkaline reflux".

\section{INTRODUCTION}

Gastro-oesophageal reflux disease (GORD) arises from increased exposure and/or sensitivity of the oesophageal mucosa to gastric contents. To date, most concepts on the frequency of gastrooesophageal reflux episodes and the efficiency of the antireflux barrier have been based on inferences derived from measurement of oesophageal pH. However, pH monitoring does not detect all gastro-oesophageal reflux events even when special $\mathrm{pH}$ analysis criteria are used, particularly when little or no acid is present in the refluxate. This is the case in both adults and infants after eating, before the gastric contents have become acidified, and it also applies to reflux in patients undergoing antisecretory therapy. Not only the acidity but also the air-liquid composition of the refluxate could be relevant in the pathogenesis of GORD.

The total rate of reflux episodes is an important indicator of the competence of the antireflux barrier and is therefore relevant when evaluating the effect of therapies directed at improving the antireflux barrier function. ${ }^{1}$ Furthermore, oesophageal or extraoesophageal symptoms of GORD may be related to less acidic $^{2-4}$ or gas reflux that is not detected by pH-metry.

\begin{abstract}
"Oesophageal or extraoesophageal symptoms of GORD may be related to less acidic or gas reflux that is not detected by $\mathrm{pH}$ metry"
\end{abstract}

Other methodologies have evolved to complement ambulatory $\mathrm{pH}$ monitoring for the detection and characterisation of gastro-oesophageal

Abbreviations: GORD, gastro-oesophageal reflux disease; LOS, lower oesophageal sphincter; HLOSR, transient lower oesophageal sphincter relaxation; DGOR, duodenogastro-oesophageal reflux 
reflux. Intraluminal electrical impedance offers the potential to detect and monitor liquid or air movement within the oesophageal lumen, ${ }^{5}$ and Bilitec, a spectrophotometric method, can detect the presence of bilirubin in the refluxate. ${ }^{6}$ These new techniques have enabled more precise evaluation of GORD and offer the opportunity to conceive gastrooesophageal reflux more broadly, both in terms of frequency and characteristics of the refluxate. As a consequence, new definitions of reflux and consistent terminology within the literature are required.

An international workshop that involved 11 experts working in the field of GORD was held in Oporto, Portugal, November 2002. The aims of this workshop were: (1) to review and discuss critically the performance of the various tools currently available for detection of gastro-oesophageal reflux events; and (2) to propose consensus based definitions of acid, non-acid, and gas reflux, applicable to both the adult and paediatric populations.

\section{TECHNICAL ASPECTS OF GASTRO-OESOPHAGEAL REFLUX DETECTION (TABLE 1) pH-metry}

Oesophageal pH-metry consists of a continuous recording of $\mathrm{pH}$ in the distal oesophagus. Detection of periods of oesophageal acidification allows for a direct diagnosis of episodes of gastro-oesophageal reflux and quantification of the exposure of the distal oesophagus to acid. ${ }^{7}$ This technique is frequently presented as a gold standard for the diagnosis of GORD and for clinical pharmacology studies. ${ }^{8}$

Table 1 Technical recommendations for gastrooesophageal reflux detection

pH-metry

- The sensitivity of $\mathrm{pH}$ monitoring to detect individual reflux events can be increased by using an optimal sampling frequency of above $1 \mathrm{~Hz}$. A sampling frequency lower than $1 \mathrm{~Hz}$ may not detect short lived reflux events.

- The specificity of $\mathrm{pH}$ monitoring can be increased by defining a required increment of $\mathrm{pH}$ drop and setting a recovery time for $\mathrm{pH}$ to return to a value greater than $\mathrm{pH} 4$.

- Even optimised pH criteria will have a low sensitivity and specificity for recognition of superimposed acid reflux episodes.

Intraluminal impedance monitoring

- In adults, it is considered adequate to measure impedance from three adjacent electrodes placed at $2 \mathrm{~cm}$ intervals, with the most distal electrode positioned $1-2 \mathrm{~cm}$ above the proximal margin of the lower oesophageal sphincter. An optimal arrangement of electrodes should detect at least $90 \%$ of all reflux episodes.

- Impedance monitoring is the only recording method that can achieve high sensitivity for detection of all types of reflux episode.

- Basal intraluminal impedance is abnormally low in patients with oesophageal mucosal abnormalities such as Barrett's columnar epithelium or oesophagitis.

Combined pH-metry and intraluminal impedance monitoring

- Combined impedance monitoring and $\mathrm{pH}$ monitoring provides a more accurate assessment of reflux than either method alone but the decision to add impedance monitoring should be determined by the primary aim of the particular investigation.

- Optimal pH criteria need to be developed for recognition of different types of reflux by evaluating concurrent impedance and $\mathrm{pH}$ recordings, as the two methods give complementary information.

Oesophageal bilirubin monitoring

- The term "oesophageal bilirubin monitoring" should be applied to the use of continuous measurement of bilirubin concentration for recognition of reflux of duodenal contents into the oesophagus.

- An individual duodenogastro-oesophageal reflux episode (DGOR) is defined as beginning when the bilirubin absorbance recorded by Bilitec is more than 0.14 and the DGOR episode is considered to be terminated when the absorbance value returns to less than 0.14 .

- While bilirubin measurement adds valuable information on the chemical nature of refluxed material, the method has some shortcomings. It requires the use of a liquid diet and cannot detect, with accuracy, either the onset or frequency of DGOR episodes.
The basic equipment requirements are a portable data logger for data storage, a $\mathrm{pH}$ electrode, a computer, and software for analysis of $\mathrm{pH}$ data. The main characteristics expected from the data logger are a frequency of sampling of the $\mathrm{pH}$ signal adjustable and great enough to detect short lasting falls in $\mathrm{pH}$, and the availability of several event markers to signal symptoms and other events during the recording. The $\mathrm{pH}$ electrode should be stable, with a fast and linear response time. The $\mathrm{pH}$ probe measures acidity only at the level of the $\mathrm{pH}$ sensor. A pH of 4 corresponds to $0.12 \mathrm{mEq}$ $\mathrm{H}^{+} / 1 .{ }^{9}$ The $\mathrm{pH}$ measurement gives no indication of the volume of the refluxate-that is, several litres of gastric contents with a $\mathrm{pH} 2$ appears the same to the $\mathrm{pH}$ probe as a few millilitres of the same material. Routine clinical $\mathrm{pH}$ measurement is performed with one distal $\mathrm{pH}$ sensor and does not allow characterisation of the proximal extent of the refluxate. Experimental studies using multiple $\mathrm{pH}$ sensors permit evaluation of the proximal extent of acid reflux. ${ }^{10}$.

\section{Sensitivity of $\mathrm{pH}$ monitoring}

The sensitivity of $\mathrm{pH}$ monitoring to detect individual acid reflux episodes is determined by sampling frequency, duration threshold, $\mathrm{pH}$ threshold, ${ }^{11}$ and the recurrence of reflux prior to $\mathrm{pH}$ recovery. Sampling frequency does not affect measurement of per cent time that $\mathrm{pH}$ is below 4 but it does affect the number of reflux events detected when the sampling frequency is too low (table 1). When greater than $1 \mathrm{~Hz}$, the sampling frequency becomes optimal (fig 1 ). ${ }^{12}$ Short lived $\mathrm{pH}$ drops may represent real reflux $^{1}$ or a loss of $\mathrm{pH}$ signal (which can be caused by air passing the $\mathrm{pH}$ sensor). The prevalence and clinical significance of short lived reflux events is currently unknown. For routine pH-metry, most equipment uses $0.25 \mathrm{~Hz}^{8}$ but it was agreed that when a $\mathrm{pH}$ data logger digitisation frequency of less than $1 \mathrm{~Hz}$ is used, the sensitivity of $\mathrm{pH}$ monitoring for recognition of reflux episodes will be impaired in proportion to the actual digitisation frequency.

\section{Specificity of $\mathrm{pH}$ monitoring}

False positive counting of reflux episodes may be due to acidic food ingestion or non-reflux related fluctuations in $\mathrm{pH}$ of approximately 4 due to body movement, respiration, or electrode drift. Suggested strategies to improve specificity included the elimination of meals from scored intervals, defining a necessary increment of $\mathrm{pH}$ drop, and setting a recovery time for the $\mathrm{pH}$ to return to a value greater than $\mathrm{pH}$ 4 (table 1). However, these modifications would also affect the sensitivity of the method.

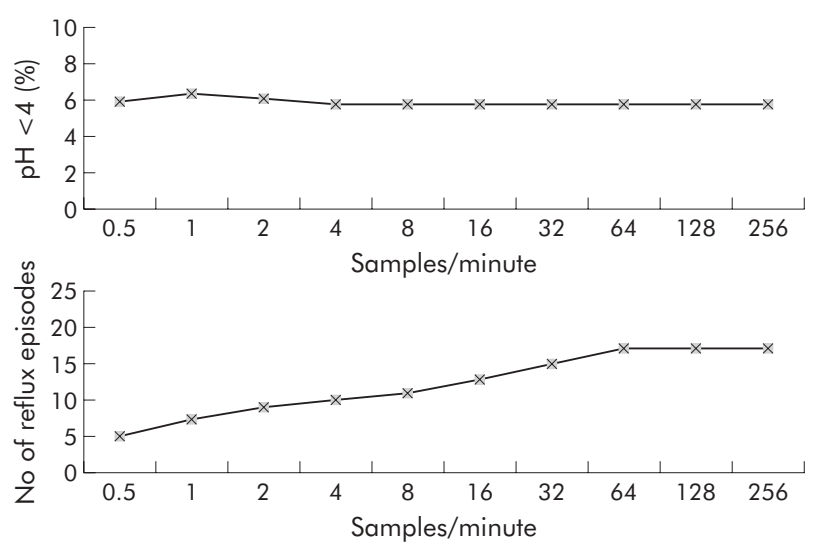

Figure 1 Effect of $\mathrm{pH}$ sampling rate on determination of oesophageal acid exposure and number of gastro-oesophageal reflux episodes. ${ }^{12}$ 


\section{Manometry}

Stationary oesophageal manometry is performed either by water perfused assemblies connected to external transducers or by solid state catheters in which the microtransducers are built into the catheter itself. For prolonged measurement of lower oesophageal sphincter (LOS) pressure, perfused and solid state specialised sensors have been developed..$^{13}$ The perfused sleeve sensor is widely used to measure LOS relaxations associated with gastro-oesophageal reflux. ${ }^{14-16}$

Using manometric parameters, Wyman et al judged that gastro-oesophageal reflux had definitely occurred with the concurrent finding of absent LOS pressure and a common cavity phenomenon that ended by primary or secondary peristalsis. ${ }^{1}$

A common cavity phenomenon consists of an abrupt increase in oesophageal body pressure to intragastric pressure level, observed in at least two distal oesophageal recording sites and persisting until the subsequent occurrence of either primary or secondary peristalsis (fig 2). ${ }^{15}$ For this phenomenon to occur, there should be relaxation and opening of both the LOS and crural diaphragm, ${ }^{17}$ and the refluxate should be of sufficient volume to envelop the distal oesophageal recording sites.

"In neonates and infants, common cavities occur during a substantially higher proportion of reflux episodes than in adults"

It was proposed at the workshop that measurement of common cavities could add secondary information on the mechanical features of individual reflux episodes but there was no consensus of agreement on this point. In neonates and infants, common cavities occur during a substantially higher proportion of reflux episodes than in adults. ${ }^{18}$ This is probably due to the fact that in this population the reflux volume relative to the luminal volume is greater and extends higher into the oesophagus. ${ }^{19}$

\section{Sensitivity of manometry}

Although common cavities are a manometric pattern clearly associated with liquid and gas reflux, ${ }^{90}$ they are a relatively

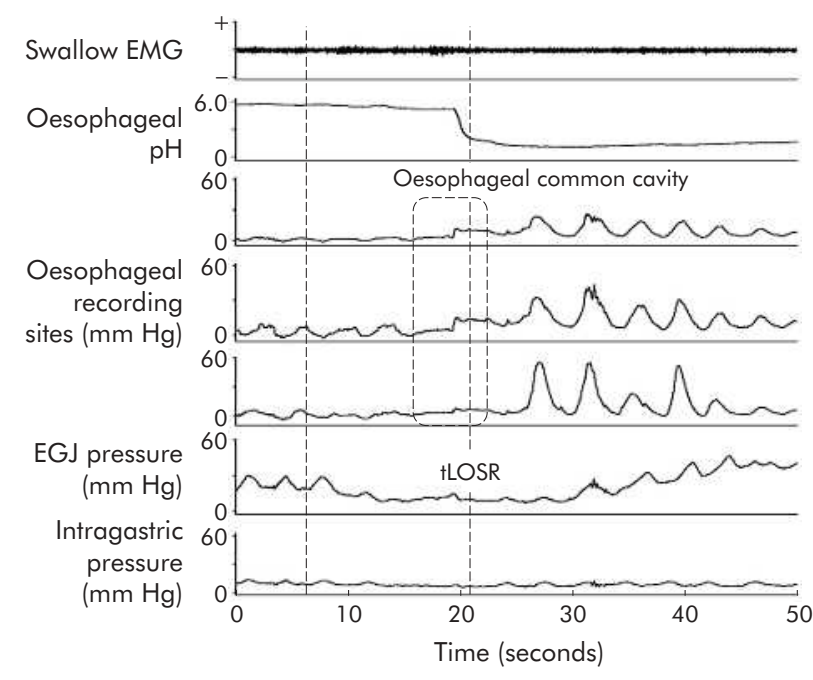

Figure 2 Example of gastro-oesophageal reflux detected by a pH manometric recording. Acid reflux (pH drop to below 4) occurs during a transient lower oesophageal sphincter relaxation (tLOSR). A common cavity phenomenon can be observed in the manometric tracing as an abrupt increase in oesophageal body pressure to intragastric pressure levels. insensitive measure of reflux. Acid reflux may occur without a common cavity if there is a refluxate of diminutive volume or a very low gastro-oesophageal pressure gradient, making it technically difficult to detect the common cavity. In a recent study by Shay and Richter, designed to assess the sensitivity of manometry, pH-metry, and impedance for detection of gastro-oesophageal reflux, manometry detected $76 \%$ of almost 1000 reflux episodes. ${ }^{21}$

\section{Specificity of manometry}

A common cavity pattern can be obtained by intraoesophageal insufflation without communication between the oesophagus and stomach. Therefore, it is a marker of oesophageal distension with gas or liquid rather than specifically of gastro-oesophageal reflux.

\section{Intraluminal impedance monitoring}

The term "intraluminal impedance monitoring" should be taken to include the concurrent measurement of impedance from multiple intraluminal recording segments. This method allows detection of gastro-oesophageal reflux based on changes in resistance to electrical current flow between two electrodes, when a liquid and/or gas bolus moves between them. ${ }^{5}$

\section{"The term "intraluminal impedance monitoring" should be taken to include the concurrent measurement of impedance from multiple intraluminal recording seg- ments"}

The impedance catheter, with mounted cylinder shaped metallic electrodes, is swallowed and positioned within the oesophageal body. The impedance (or resistance) to the current flow delivered between two electrodes depends on the electrical conductivity of the environment surrounding the electrodes (luminal content, mucosa, wall thickness) as well as the cross sectional area. When a liquid bolus with high electrical conductivity bridges two electrode rings, impedance decreases. In contrast, a gas bolus with very low electrical conductivity increases impedance. Furthermore, opening of the lumen by a bolus passing along the measuring segment results in a drop in impedance whereas luminal closure causes impedance to increase. ${ }^{5}$ The difference in patterning of the electrical conductivity of liquid, gas, or mixed (liquid-gas) intraluminal content allows distinction among these luminal contents whereas the sequence of impedance changes in different segments allows recognition of flow in either aboral (swallow related) or oral (reflux) directions. Impedance does not measure the acidity of the intraluminal content. ${ }^{22}$

\section{Liquid reflux}

Gastro-oesophageal reflux is detected as an orally progressing drop in impedance, starting at the level of the LOS and propagating to more proximal impedance measuring segments (fig 3). ${ }^{19}$ Previous studies and an experimental validation study in cats $^{20} 23$ using simultaneous impedance and fluoroscopy showed that liquid reflux produced an impedance drop in the oesophagus of $46.5 \%$ from baseline values, with the result that subsequent studies used drops of $50-60 \%$ in impedance to declare the presence of liquid within the oesophagus. ${ }^{9} 190^{24-29}$ Most participants felt that the 50\% reduction was too stringent and that the pattern of reflux was as important. Impedance is very sensitive for detection of small volumes of liquid, and similar drops in impedance are observed with boluses of $1 \mathrm{ml}$ and $10 \mathrm{ml}^{30}$ Therefore, to date, the intraluminal impedance technique cannot estimate the volume of the refluxate. 


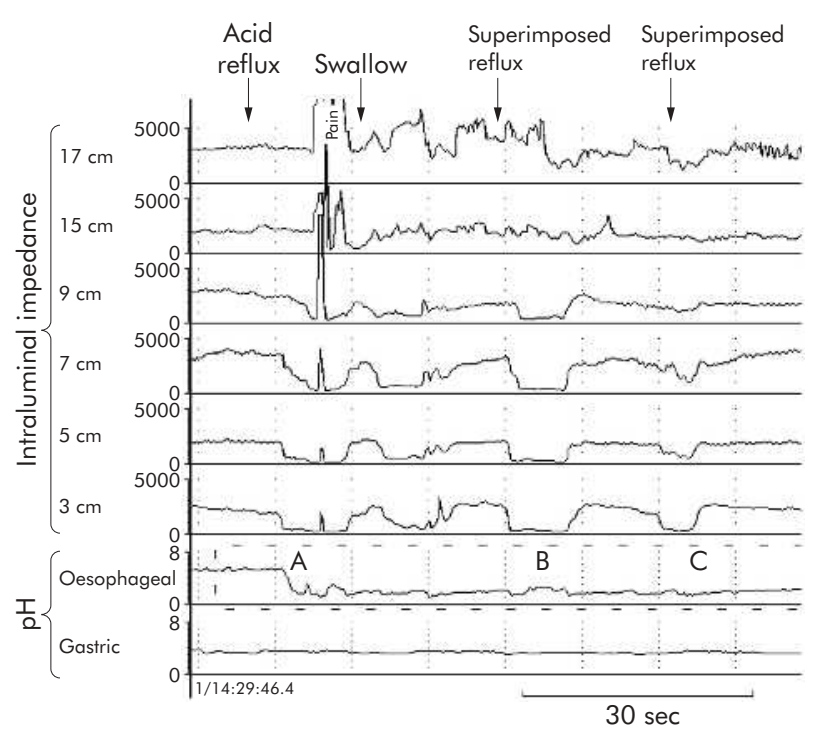

Figure 3 Oesophageal intraluminal impedance monitoring combined with oesophageal and gastric pH measurements. Gastro-oesophageal reflux is detected as an orally progressing drop in impedance, starting at the level of the lower oesophageal sphincter and propagating to more proximal impedance measuring segments. In this tracing, three reflux episodes can be observed: (A) acid reflux (mixed liquid-gas); (B) and (C), superimposed reflux episodes (liquid).

\section{Gas reflux}

Intraluminal air (which has a very low electrical conductivity) provokes a rapid $(3 \mathrm{k} \Omega / \mathrm{s})$ and pronounced rise in impedance. ${ }^{20}$ In the absence of swallowing, gastro-oesophageal reflux of gas is detected as an almost simultaneous or rapidly orally progressing rise in oesophageal impedance in at least two oesophageal impedance channels. ${ }^{10}{ }^{20}$ In the upright position, intraluminal air is better detected by impedance recordings in the most proximal oesophagus.

The criteria for recognition of liquid and gas reflux events in neonates, infants, and children are essentially the same as in adults (Omari T, personal communication). ${ }^{19} 2425$

\section{Location of impedance electrodes}

For reliable recognition of reflux episodes, it was agreed that the centre of the most distal impedance channel should be $1-$ $2 \mathrm{~cm}$ above the proximal margin of the LOS (table 1). This location allows recognition of the so-called short segment reflux - that is, reflux restricted to the very distal oesophagus that does not reach $5 \mathrm{~cm}$ above the LOS. ${ }^{10} 2031$

When there is an abnormally low baseline intraluminal impedance in the most distal oesophageal recording segment (for example, in patients with oesophagitis), ${ }^{32}$ the impedance drop recorded by this may not be sufficient to reach the defined threshold. It is possible to use the more proximal channels however and a liquid reflux episode is proven when there is an abrupt reduction in impedance in the next two adjacent recording segments. It was agreed therefore that reliable recognition of reflux episodes requires impedance recording from three adjacent $2 \mathrm{~cm}$ long segments in the distal oesophagus.

\section{"During gastro-oesophageal reflux, drops in impedance in the mid and upper oesophagus indicate the proximal extent of the liquid refluxate"}

During gastro-oesophageal reflux, drops in impedance in the mid and upper oesophagus indicate the proximal extent of the liquid refluxate. ${ }^{33}$ So far there are no studies that have compared the proximal extent of reflux measured with impedance with data on this from other techniques (that is, scintigraphy or radiology).

\section{Sensitivity of impedance monitoring}

The sensitivity of impedance has been determined by comparing its ability to detect reflux with that of manometry and $\mathrm{pH}$-metry. In fasting recumbent patients with severe GORD, impedance detected $95 \%$ of 408 reflux events diagnosed by combined manometry and pH-metry. ${ }^{934}$ Compared with manometry, impedance detected reflux in 92-99\% of common cavities. ${ }^{9}$ Compared with pH-metry, 97$98 \%$ of acid reflux events were detected by impedance under both stationary and ambulatory conditions. ${ }^{27} 28$ From published evidence, it was concluded that an optimal arrangement of impedance electrodes in adults has a sensitivity of at least $90 \%$ for detection of all reflux episodes (table 1). The sensitivity of impedance for reflux recognition may be affected by the occurrence of very low baseline impedance values, such as may be observed in the presence of oesophagitis (fig 4). Preliminary studies have found that impedance changes due to acute oesophagitis are reversed when this heals. ${ }^{35}$

While the presence of oesophagitis does not preclude the recognition of reflux during visual analysis, it can make automated recognition difficult. Another cause of low basal impedance is the presence of Barrett's columnar epithelium (table 1). There is a reasonable correlation between the length of the columnar epithelium, as measured by impedance, and endoscopy. ${ }^{32}$

\section{Specificity of impedance monitoring}

During combined impedance-pH-manometric studies, false positive impedance changes (that is, a typical impedance retrograde flow reflux pattern without any $\mathrm{pH}$ or manometric suggestion of reflux) were rare (table 1). One source of error is swallow related drops in impedance. ${ }^{34}$ False negative impedance (that is, $\mathrm{pH}$ drops without impedance change) can be observed during slow $\mathrm{pH}$ drifts or during reflux events that occur soon after swallowing.

\section{Bilitec monitoring}

Bilitec is a monitoring system that can detect duodenogastrooesophageal reflux (DGOR) by utilising the optical properties of bilirubin (table 1). ${ }^{36-41}$ Although Bilitec does not measure concentrations of duodenal components, a good correlation has been found between bilirubin content and the concentrations of pancreatic enzymes in aspirated refluxate, suggesting that bilirubin is a good tracer for duodenal components in the gastro-oesophageal refluxate. ${ }^{36}{ }^{37}$ The working principle of Bilitec is that detection in the oesophageal lumen of any absorption near $450 \mathrm{~nm}$ suggests the presence of bilirubin, and therefore DGOR. There was a consensus therefore that the term "oesophageal bilirubin monitoring" should be applied to the use of continuous measurement of bilirubin concentration for recognition of reflux of duodenal contents into the oesophagus.

\section{"Bilitec is a monitoring system that can detect duodeno- gastro-oesophageal reflux (DGOR) by utilising the optical properties of bilirubin"}

DGOR data measured by Bilitec are usually presented as "\% time bilirubin absorbance is higher than 0.14 " (table 1 ). This cut off value has been selected because studies have shown that values below this number could be due to suspended particle and mucus present in the gastric contents. $^{36}{ }^{37}$ 


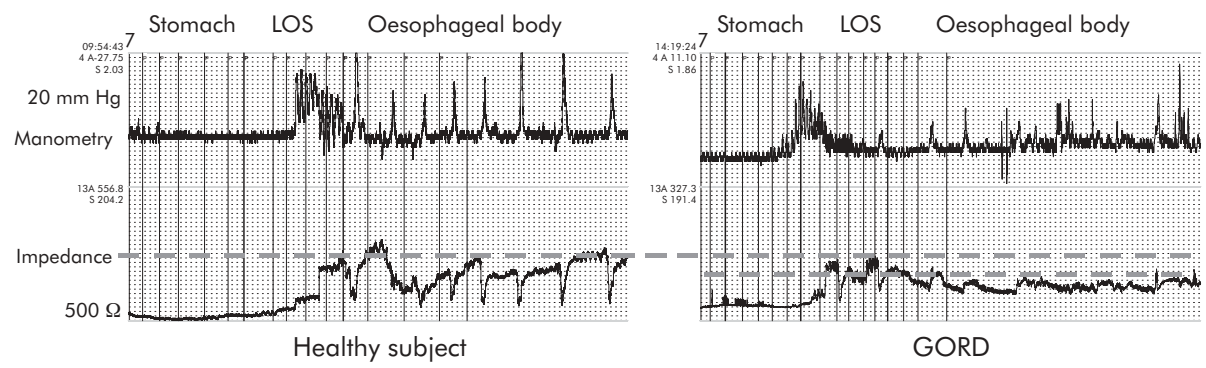

Figure 4 Tracings during a slow pull through of a combined manometric impedance catheter across the gastro-oesophageal junction. Patients with gastro-oesophageal reflux disease (GORD) have lower basal impedance values in the distal oesophageal body compared with healthy subjects. ${ }^{31}$ LOS, lower oesophageal sphincter.

\section{Sensitivity of bilirubin measurement}

The sampling rate of the Bilitec probe is only once per eight seconds. The software averages between the absorbencies calculated over two successive samples to decrease the noise of the measurements. ${ }^{37}$ This is a very low sampling frequency compared with $\mathrm{pH}$ monitoring and suggests that this technique is unable to detect with accuracy the time of onset of bilirubin reflux into the oesophagus. However, there are no data comparing the number of DGOR events at different sampling frequencies.

\section{Specificity of bilirubin measurement}

The spectrophotometric capsule has a gap that is traversed by the measuring light beam. Solid material can be trapped in this gap and so interfere with the function of the sensor. Consistent with this, several studies have demonstrated the need to use a liquid special diet, as major meal artefacts, thought to be due to food being trapped in the capsule gap, are observed in up to $20 \%$ of the recordings where a solid diet has been used. ${ }^{42}$ A liquid diet also allows better correlation with simultaneous $\mathrm{pH}$ monitoring. ${ }^{43}$ It was agreed that it is impossible for bilirubin monitoring with the Bilitec apparatus to reflect with accuracy the number of DGOR episodes because of the several technical limitations in the functioning of this equipment (table 1).

\section{REFLUX SUBCATEGORIES (TABLE 2)}

\section{Acid reflux}

To date, studies reported in the literature ${ }^{710^{11}}$ have used different definitions for acid reflux. Acid reflux is diagnosed by pH-metry. There was strong consensus agreement among the group that acid reflux should be defined as "reflux episodes that decrease oesophageal $\mathrm{pH}$ across 4 , or reflux that occurs when oesophageal $\mathrm{pH}$ is already below 4 " (table 2 ). A caveat has to be applied to the above definition of acid reflux however as a substantial proportion of $\mathrm{pH}$ drops to below 4 are not due to gastro-oesophageal reflux (fluctuations of $\mathrm{pH}$ around 4 due to movement, respiration, or electrode drift). It should be possible to increase the sensitivity of $\mathrm{pH}$ measure-

Table 2 Recommended definitions for reflux subcategories

- "Acid reflux" should be used to describe refluxed gastric juice with a $\mathrm{pH}$ less than 4 which can either reduce the $\mathrm{pH}$ of the oesophagus to below 4 or occur when oesophageal pH is already below 4 . "Superimposed acid reflux" should be used to describe an acidic reflux episode that occurs before oesophageal $\mathrm{pH}$ has recovered to above 4.

- "Weakly acidic reflux" should be used to describe reflux events that result in an oesophageal pH between 4 and 7 .

- "Weakly alkaline reflux" should be reserved for reflux episodes during which nadir oesophageal $\mathrm{pH}$ does not drop below 7 . ment by increasing the sampling frequency ${ }^{12}$ and by removing duration as a criterion of reflux. Additionally, increasing the $\mathrm{pH}$ threshold from 4 to 5 almost doubles the number of reflux events detected. The specificity of $\mathrm{pH}$ measurement may be improved by setting a minimum interval between events ( 10 seconds), minimum duration of events (three seconds), minimum drop in $\mathrm{pH}$ ( $1 \mathrm{pH}$ unit), minimum $\mathrm{pH}$ drop rate $(0.5 \mathrm{pH}$ units per second), or the hysteresis criterion (for example, fall to 3.8 , rise to 4.2 ). It was also suggested that the specificity of $\mathrm{pH}$ measurement could be improved if the $\mathrm{pH}$ recovery level was increased to 5 instead of 4, as many non-reflux related fluctuations in $\mathrm{pH}$ occur at around $\mathrm{pH} 4 .^{44}$ The use of combined $\mathrm{pH}$ monitoring and impedance measurement would permit detection of acid reflux episodes and would also obviate the need to use duration criteria, as the impedance criteria define whether or not reflux has occurred.

The occurrence of reflux episodes when the basal oesophageal pH is already below 4 was discussed in some detail. These episodes represent a special category of acid reflux and consensus was obtained that they should have a unique descriptor. This type of reflux was previously described as "re-reflux". ${ }^{45}$ However, this name implies that reflux occurred, it was cleared, and that the same material was then refluxed again. It was suggested that this type of acid reflux should be renamed more accurately as "superimposed acid reflux", as it represents the occurrence of a further reflux episode before the contents of the oesophagus have been cleared from the previous reflux episode (table 2). This is an important phenomenon underlying the delay in oesophageal clearance, particularly in patients with a hiatal hernia. ${ }^{46}{ }^{47} \mathrm{It}$ was agreed that even if optimal $\mathrm{pH}$ criteria and digitisation frequencies were used, pH-metry would have a low sensitivity and a low specificity for the recognition of "superimposed acid reflux" (fig 3). As many as 33\% of superimposed acid

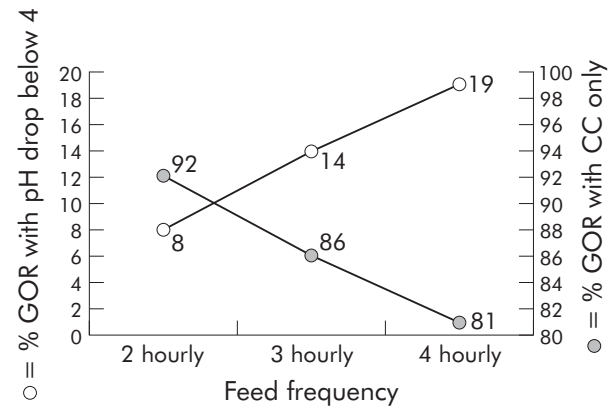

Figure 5 In neonates, the high frequency of feeds results in a significant number of reflux episodes (detected as common cavities (CC)) not causing a drop in oesophageal $\mathrm{pH}$ across $4 .{ }^{18} \mathrm{GOR}$, gastrooesophageal reflux. 
reflux events (detected by manometry) are associated with no change in $\mathrm{pH} .{ }^{1}$ Conversely, it is also known that a number of $\mathrm{pH}$ drops occurring when the basal oesophageal $\mathrm{pH}$ is below 4 (which would be classified on the basis of $\mathrm{pH}$ as "superimposed" reflux) are due to fluctuations in $\mathrm{pH}$ due to movement, respiration, or electrode drift and are not actually due to reflux. Impedance monitoring is able to detect "superimposed" reflux episodes where no change in pH occurs or when the fall in $\mathrm{pH}$ is $<0.5$ units. ${ }^{9}$

\section{Weakly acidic reflux}

If an acid reflux episode is defined as a drop in $\mathrm{pH}$ across 4 for at least four seconds, it is likely that the number of reflux episodes will be underestimated by approximately 50\% during both the interdigestive and first three postprandial hours in adults. ${ }^{148}$ Additionally, when these $\mathrm{pH}$ criteria are applied to neonates and infants, the high frequency of feeds would result in even more reflux episodes $(>66 \%)$ not causing a drop in oesophageal pH across 4 (fig 5). ${ }^{18}$

The terminology used to describe reflux episodes in which the nadir $\mathrm{pH}$ lies between 4 and 7 was discussed in some detail (table 2 ). In cases where the $\mathrm{pH}$ falls by at least 1 unit, but does not fall below 4, it was decided to accept the term "weakly acidic reflux" and to reject the old terminology of "minor or low acid reflux". The upper limit of pH 7 was chosen to define the limit of weakly acidic events, as any fall below pH 7 contains some acid. Some experts felt however that detectable $\mathrm{pH}$ falls usually start from $\mathrm{pH}$ 6.5, and so consensus agreement was not obtained on this point.

The use of combined $\mathrm{pH}$ monitoring and impedance measurement would permit more accurate detection of weakly acidic reflux episodes.

\section{Non-acid reflux}

The literature contains different definitions of the term "nonacid" reflux. It has been used to refer to: (a) reflux episodes diagnosed by manometry or scintigraphy without $\mathrm{pH}$ drops across $4^{49}$; (b) DGOR events diagnosed with Bilitec monitoring $^{50}$; (c) reflux events diagnosed by impedance monitoring with no change in $\mathrm{pH}$ or a drop in $\mathrm{pH}$ that does not reach $4^{28}$; and (d) reflux events diagnosed by impedance monitoring with no change in $\mathrm{pH}$ or $\mathrm{pH}$ fall of less that $1 \mathrm{pH}$ unit. ${ }^{20}$

It was decided that definitions should be based on the $\mathrm{pH}$ of the refluxate, as defined chemically. A pH of 7 should be the cut off between "weakly acidic" and "weakly alkaline reflux" (table 2, fig 6).

In many cases, the basal oesophageal pH is between 5 and 6 and a reflux event detected by impedance does not change the oesophageal pH. This is frequently the case in infants

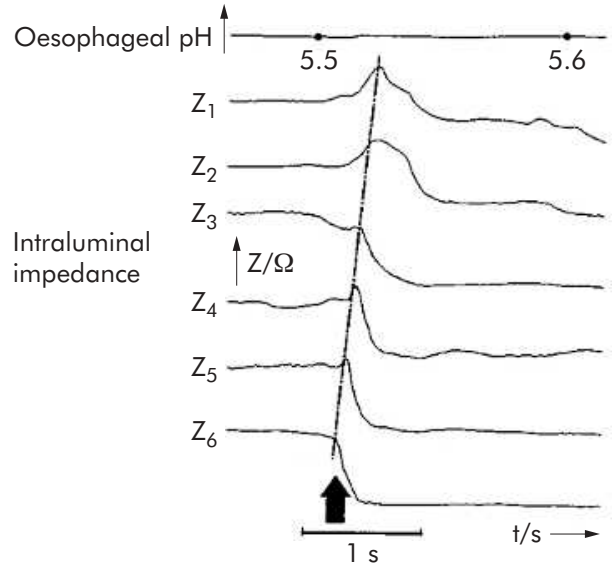

Figure 7 In infants, basal oesophageal $\mathrm{pH}$ is often between 5 and 6 and a reflux event detected by impedance might not change the oesophageal $\mathrm{pH} .^{19}$

(fig 7). It was suggested that it would be wrong to label these types of reflux as "non-acid", as the refluxate is weakly acidic, even though it does not decrease the previous oesophageal $\mathrm{pH}$.

\section{"Based on the $\mathrm{pH}$ of gastric contents, the majority of reflux episodes constitute weakly acidic reflux"}

In infants and neonates, gastric $\mathrm{pH}$ is often higher than oesophageal $\mathrm{pH}$, and therefore it is difficult to define the type of reflux episode. ${ }^{18}$ The question arises as to whether a reflux episode should be defined as "non-acid reflux" because it increases oesophageal pH, or "weakly acidic reflux" as the refluxate content is still acidic. In neonates, generally, oesophageal $\mathrm{pH}$ does not rise as high as 7 and therefore it would not strictly meet the new definition of "weakly alkaline reflux". Participants felt strongly however that terminology proposed by the consensus report should be applicable to both adults and neonates and it was decided that the term "weakly alkaline reflux" should be reserved for reflux episodes during which nadir oesophageal $\mathrm{pH}$ does not drop below 7 (table 2). Therefore, the previous descriptor "non-acid reflux" can be renamed as "weakly alkaline reflux" that by definition is a very exceptional event. Based on the $\mathrm{pH}$ of gastric contents, the majority of reflux episodes constitute weakly acidic reflux.

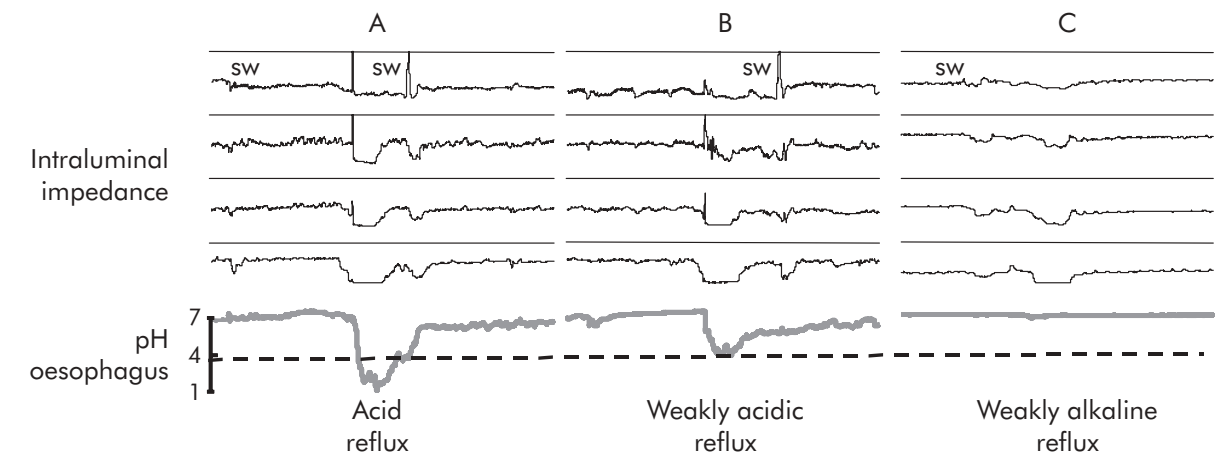

Figure 6 Definitions of reflux are based on the $\mathrm{pH}$ of the refluxate. Acid reflux $(\mathrm{A})$ is defined as reflux that reduces oesophageal $\mathrm{pH}$ to below 4 or reflux that occurs when oesophageal $\mathrm{pH}$ is already below 4 . Superimposed acid reflux is a subcategory of acid reflux. Weakly acidic reflux (B) is defined as a pH fall of at least 1 unit where the $\mathrm{pH}$ does not fall below 4 , and a pH of 7 is the cut off between "weakly acidic" and "non-acid reflux". Weakly alkaline reflux $(C)$ is defined as a reflux episode during which nadir oesophageal pH does not drop below 7. 


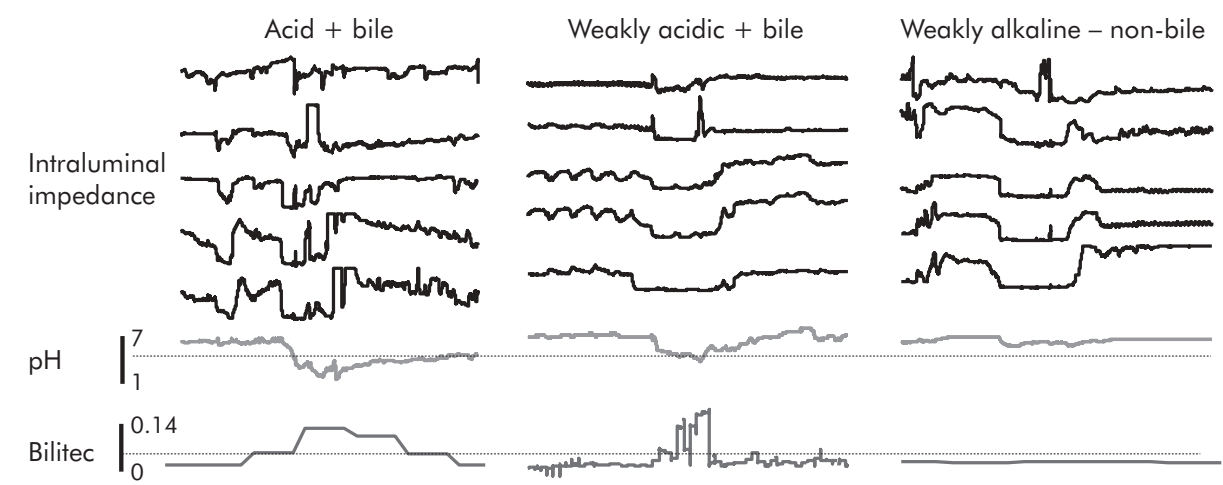

Figure 8 Simultaneous $\mathrm{pH}$ impedance-Bilitec recordings: oesophageal bilirubin concentration monitoring adds information about the chemical nature of acid and non-acid material that refluxes into the oesophagus. Weakly acidic and weakly alkaline reflux may or may not include duodenal contents

\section{Bilirubin reflux}

Bilirubin monitoring provides a different approach from the other methods of reflux monitoring as it is concerned with the chemical composition of the refluxate. It detects bilirubin in the refluxate, which indicates that DGOR has occurred. A bilirubin reflux event is defined as an increase in bilirubin absorbance to above 0.14 , as recorded by Bilitec, and is considered to be terminated when the absorbance value returns to less than $0.14 .^{37}$

Consensus was obtained that the term "oesophageal bilirubin monitoring" should be applied to the use of continuous measurement of bilirubin concentration for recognition of reflux of duodenal contents into the oesophagus. Impedance and pH-metry can detect acid and non-acid reflux but cannot describe its composition. In spite of its technical limitations, oesophageal bilirubin concentration monitoring adds information about the chemical nature of acid and non-acid material that refluxes into the oesophagus (fig 8).

\section{Liquid/gas reflux}

Oesophageal reflux can now be defined both in terms of its acidity and its physical state (liquid-gas). gastro-oesophageal reflux The advantages of using impedance monitoring to differentiate between liquid and gas reflux were described above (see "Technical aspects of gastro-oesophageal reflux detection" above). "Liquid reflux" is defined by the pattern of an orally progressing drop in impedance of at least $50 \%$ in at least three adjacent distal oesophageal recording segments. Provided that only reflux can cause such a typical aborally progressive pattern of rapid drops in impedance, a revised threshold would be acceptable. If these drops are recorded from electrode pairs in the mid and upper oesophagus, this indicates the extent of travel of liquid up the oesophagus. Gas reflux, on the other hand, results in a pattern of abrupt retrograde or simultaneous increases in impedance over any two segments, being independent of swallowing.

Mixed reflux of gas and liquid is more frequent than pure liquid reflux, both in healthy subjects and in patients with GORD. ${ }^{33}$ When gas and liquid are present in the refluxate, the impedance increase (indicative of gas) can precede the impedance drop (indicative of liquid), or vice versa. Whether the gas-liquid or liquid-gas sequence represents small amounts of liquid in a large volume of gas, small amounts of gas in a large volume of liquid, or a fine mix of liquid and gas cannot be determined without another, more sensitive, marker of gas reflux as a gold standard.

\section{CONCLUSIONS}

Impedance monitoring is the only recording method that can achieve high sensitivity for detection of all types of reflux episode. Even with optimisation of methods, the sensitivity and specificity of $\mathrm{pH}$ monitoring will not approach that of impedance monitoring for recognition of occurrence of individual reflux episodes.

Reflux is best detected by impedance and its acidity characterised by pH-metry. A small percentage of acid reflux events may occur as slow pH drops that are not detected by impedance, suggesting that the combination of both techniques is better than pH-metry or impedance monitoring alone. Therefore, combined $\mathrm{pH}$ and intraluminal impedance monitoring allows detection of all reflux events and gives the best possible evaluation of the function of the antireflux barrier. Bilirubin measurement is useful to determine the presence of duodenal content in the refluxate but the current technique is limited in its ability to detect the onset or frequency of individual DGOR events.

"Reflux is best detected by impedance and its acidity characterised by $\mathrm{pH}$-metry"

The different available techniques for reflux monitoring offer the opportunity to conceive gastro-oesophageal reflux more broadly, both in terms of frequency and characteristics of the refluxate. The criteria developed for their use apply to both adults and children or neonates and these techniques may be used alone or in combination, according to the clinical scenario. The decision to add impedance to $\mathrm{pH}$ monitoring should be determined by the primary aim of the particular investigation. For example, in diagnostic studies where patients with GORD are "off" antisecretory therapy, pH-metry alone may be sufficient in the majority of cases. However, in adult patients with GORD and persistent symptoms despite adequate therapy, or in neonates, combined $\mathrm{pH}$-impedance monitoring may prove superior. To date, the lack of automated analysis remains a significant limitation of impedance monitoring. However, algorithms for automated analysis of prolonged $\mathrm{pH}$-impedance monitoring are currently under development. Clinical studies and outcome data will ultimately define the usefulness of these new techniques and definitions for reflux monitoring.

\section{ACKNOWLEDGMENTS}

We would like to thank Dr Madeline Frame for assistance with the preparation of this manuscript. The workshop was supported by an educational grant from Astra Zeneca

\section{CONTRIBUTORS}

Professor L Akkermans, Department of Surgery, University Hospital, Utrecht PO Box 8500, 3508 GA Utrecht, the Netherlands; Professor D Castell, Director, Esophageal Disorders Program, Medical University of South Carolina, 96 Jonathan Lucas St STE 210, PO Box 250327, 
Charleston SC 29625, USA; Professor G Davidson, Centre for Paediatric and Adolescent Gastroenterology, Women's and Children's Hospital and Department of Paediatrics, University of Adelaide, North Adelaide, Australia; Professor J Dent, Department of Gastroenterology, Hepatology, and General Medicine, Level 7 North Wing, Royal Adelaide Hospital, North Terrace, Adelaide, South Australia 5000; Associate Professor $R$ Holloway, Department of Gastroenterology, Hepatology, and General Medicine, Level 7 North Wing, Royal Adelaide Hospital, North Terrace, Adelaide, South Australia 5000; Professor PJ Kahrilas, Northwestern University, The Feinberg School of Medicine, Division of Gastroenterology, 676 North St Clair St, Suite 1400, Chicago, Illinois 60611-2951, USA; Dr T Omari, Centre for Paediatric and Adolescent Gastroenterology, Women's and Children's Hospital and Department of Paediatrics, University of Adelaide, North Adelaide, Australia; $\operatorname{Dr} S$ Shay, Gastroenterology Service, Cleveland Clinic Foundation, Cleveland, Ohio 44195, USA; Associate Professor D Sifrim, Center for Gastroenterological Research, Department of Gastroenterology, University Hospitals KU Leuven, Herestraat 49, B-3000 Leuven, Belgium; Professor A Smout, Academisch Ziekenhuis Utrecht, Heidelberglaan 100, 3584 CX Utrecht, the Netherlands; Professor J Tack, Center for Gastroenterological Research, Department of Gastroenterology, University Hospitals KU Leuven, Herestraat 49, B-3000 Leuven, Belgium.

\section{Authors' affiliations}

D Sifrim, Centre for Gastroenterological Research, Faculty of Medicine, Catholic University of Leuven, Belgium

D Castell, Director, Esophageal Disorders Program, Medical University of South Carolina, Charleston, South Carolina, USA

J Dent, Department of Gastroenterology, Hepatology, and General Medicine, Royal Adelaide Hospital, Adelaide, Australia

P J Kahrilas, Division of Gastroenterology, Northwestern University's Feinberg School of Medicine, Chicago, Illinois, USA

\section{REFERENCES}

1 Wyman JB, Dent J, Holloway RH. Changes in oesophageal pH associated with gastro-oesophageal reflux. Are traditional criteria sensitive for detection of reflux? Scand J Gastroenterol 1993;28:827-32.

2 Dent J, Holloway RH, Toouli J, et al. Mechanisms of lower oesophageal sphincter incompetence in patients with symptomatic gastro-oesophageal reflux. Gut 1988;29:1020-8.

3 Breumelhof R, Nadorp JH, Akkermans LM, et al. Analysis of 24-hour esophageal pressure and $\mathrm{pH}$ data in unselected patients with noncardiac chest pain. Gastroenterology 1990;99:1257-64

4 Mattioli S, Pilotti V, Felice V, et al. Ambulatory 24-hr pH monitoring of esophagus, fundus, and antrum. A new technique for simultaneous study of gastro-esophageal and duodenogastric reflux. Dig Dis Sci 1990;35:929-38.

5 Silny J. Intraluminal multiple electrical impedance procedure for measurement of gastro-intestinal motility. J Gastrointest Motil 1991;3:151-62.

6 Bechi P, Paucciani F, Baldini F, et al. Long-term ambulatory enterogastric reflux monitoring. Validation of a new fiberoptic technique. Dig Dis Sci 1993;38:1297-306.

7 Johnson LF, De Meester TR. Development of the 24-hour intraesophageal pH monitoring composite scoring system. J Clin Gastroenterol 1986;1:747-67.

8 Kahrilas PJ, Quigley EM. Clinical esophageal pH recording: a technical review for practice guideline development. Gastroenterology 1996; 110:1982-96

9 Shay S, Bomeli S, Richter J. Multichannel intraluminal impedance accurately detects fasting, recumbent reflux events and their clearing. Am J Physiol Gastrointest Liver Physiol, 2002;283:G376-83.

10 Weusten BL, Akkermans LM, van Berge-Henegouwen GP, et al. Spatiotemporal characteristics of physiological gastroesophageal reflux. Am J Physiol 1994;266(Pt 1):G357-62.

11 Schindlbeck NE, Ippisch H, Klauser AG, et al. Which pH threshold is best in esophageal pH monitoring? Am J Gastroenterol 1991;86:1138-41.

12 Emde C, Garner A, Blum AL. Technical aspects of intraluminal pH-metry in man: current status and recommendations. Gut 1987;28:1177-88.

13 Ergun GA, Kahrilas PJ. Clinical applications of esophageal manometry and $\mathrm{pH}$ monitoring. Am J Gastroenterol 1996:91:1077-89.

14 Dent J. A new technique for continuous sphincter pressure measurement. Gastroenterology 1976;71:263-7.

15 Dent J, Dodds WJ, Friedman RH, et al. Mechanism of gastroesophageal reflux in recumbent asymptomatic human subjects. J Clin Invest 1980;65:256-67.

16 Shi G, Ergun GA, Manka M, et al. Lower esophageal sphincter relaxation characteristics using a sleeve sensor in clinical manometry. Am J Gastroenterol 1998;93:2373-9

17 Pouderoux P, Verdier E, Kahrilas PJ. Patterns of esophageal inhibition during swallowing, pharyngeal stimulation, and transient LES relaxation. Am J Physiol Gastrointest Liver Physiol 2003;284:G242-7.

18 Omari TI, Barnett CP, Benninga MA, et al. Mechanisms of gastro-oesophageal reflux in preterm and term infants with reflux disease. Gut 2002;51:475-9.
19 Skopnik H, Silny J, Heiber O, et al. Gastroesophageal reflux in infants: evaluation of a new intraluminal impedance technique. J Pediatr Gastroenterol Nutr 1996;23:591-8.

20 Sifrim D, Silny J, Holloway RH, et al. Patterns of gas and liquid reflux during transient lower esophageal sphincter relaxation. A study using intraluminal electrical impedance. Gut 1999;44:47-54.

21 Shay S, Richter JE. Direct comparison of impedance, common cavity, and pH probe in detecting daytime GER's and their characteristics. Gastroenterology 2003; 124:A534.

22 Nguyen HN, Silny J, Matern S. Multiple intraluminal electrical impedancometry for recording of upper gastrointestinal motility: current results and further implications. Am J Gastroenterol 1999;94:306-17.

23 Nguyen HN, Silny J, Albers D, et al. Dynamics of esophageal bolus transport in healthy subjects studied using multiple intraluminal impedancometry. Am J Physiol 1997;273(Pt 1):G958-64.

24 Wenzl TG, Silny J, Schenke S, et al. Gastroesophageal reflux and respiratory phenomena in infants: status of the intraluminal impedance technique. J Pediatr Gastroenterol Nutr 1999;28:423-8.

25 Wenzl TG, Moroder C, Trachterna M, et al. Esophageal pH monitoring and impedance measurement: a comparison of two diagnostic tests for gastroesophageal reflux. J Pediatr Gastroenterol Nutr 2002;34:519-23.

26 Sifrim D, Holloway R, Silny J, et al. Acid, nonacid, and gas reflux in patients with gastro-esophageal reflux disease during ambulatory $24-\mathrm{hr} \mathrm{pH}-$ Impedance recordings. Gastroenterology 2001;120:1588-98.

27 Shay S, Tutuian R, Vela M, et al. Twenty-four hour ambulatory multichannel intraluminal impedance and $\mathrm{pH}$ : A multicenter report of normal values from 45 healthy volunteers. Gastroenterology 2002;122:A577.

28 Vela M, Camacho-Lobato L, Srinivasan R, et al. Simultaneous intraesophageal impedance and $\mathrm{pH}$ measurement of acid and nonacid gastro-esophagea reflux: Effect of omeprazole. Gastroenterology 2001;120:1599-606.

29 Vela MF, Tutuian R, Katz PO, et al. Baclofen decreases acid and non-acid post-prandial gastro-oesophageal reflux measured by combined multichannel intraluminal impedance and $\mathrm{pH}$. Aliment Pharmaco Ther 2003;17:243-51.

30 Srinivasan R, Vela MF, Katz PO, et al. Multichannel intraluminal impedance (MII): A highly sensitive technique to detect small intraesophageal volumes. Gastroenterology 2000;118(Pt 1, suppl 2):2636.

31 Fletcher J, Henry EB, Wirz A, et al. Short segment acid reflux: Markedly increased acid load on distal esophagus revealed by novel pHmetry. Gastroenterology 2000;118(suppl 2):A448.

32 Sifrim D, Holloway R, Tack J, et al. Impedance patterns at the gastroesophageal junction and distal esophagus in patients with Barrett's esophagus. Gastroenterology 2000;118:A489.

33 Sifrim D, Holloway R, Silny J, et al. Composition of the postprandial refluxate in patients with gastroesophageal reflux disease. Am J Gastroenterol 2001; $96: 647-55$

34 Shay SS, Vela M, Richter J. Multichannel intraluminal impedance (MII) detects reflux events (RE) during the vulnerable period after a swallow that are missed by $\mathrm{pH}$ probe and manometry. Gastroenterology 2002;122(suppl 1):T1120.

35 Zhang X, Silny J, Tack J, et al. Effect of acute esophagitis on basal esophageal intraluminal electric impedance. Gastroenterology 2003;124:A534.

36 Bechi P, Pucciani F, Baldini F, et al. Long-term ambulatory enterogastric reflux monitoring. Validation of a new fiberoptic technique. Dig Dis Sci 1993:38:1297-306.

37 Vaezi MF, LaCamera RG, Richter JE. Validation studies of Bilitec 2000: an ambulatory duodenogastric reflux monitoring system. Am J Physiol 1994;267:G1050-7.

38 Vaezi MF, Singh S, Richter JE. Role of acid and duodenogastric reflux in esophageal mucosal injury: a review of animal and human studies. Gastroenterology 1995;108:1897-907.

39 Champion G, Richter JE, Vaezi MF, et al. Duodenogastro-esophageal reflux: relationship to $\mathrm{pH}$ and importance in Barrett's esophagus. Gastroenterology 1994; 107:747-54.

40 Caldwell MTP, Lawlor P, Byrne PJ, et al. Ambulatory oesophageal bile monitoring in Barrett's oesophagus. Br J Surg 1995;82:657-60.

41 Kaver WKH, Burdiles P, Ireland AP, et al. Does duodenal juice reflux into the esophagus of patients with complicated GERD? Evaluation of a fiberoptic sensor for bilirubin. Am J Surg 1995;169:98-103.

42 Barrett MW, Myers JC, Watson DI, et al. Dietary interference with the use of Bilitec to assess bile reflux. Dis Esophagus 1999;12:60-4.

43 Koek GH, Tack J, Sifrim D, et al. The role of acid and duodenal gastroesophageal reflux in symptomatic GERD. Am J Gastroenterol 2001;96:2033-40.

44 Weusten BL, Roelofs JM, Akkermans LM, et al. Objective determination of $\mathrm{pH}$ thresholds in the analysis of $24 \mathrm{~h}$ ambulatory oesophageal $\mathrm{pH}$ monitoring. Eur J Clin Invest 1996;26:151-8.

45 Shay SS, Richter JE. Importance of additional reflux events during esophageal acid clearing. Dig Dis Sci 1998;43:95-102.

46 Mittal RK, Lange RC, McCallum RW. Identification and mechanism of delayed esophageal acid clearance in subjects with hiatus hernia. Gastroenterology 1987;92:130-5.

47 Kahrilas PJ. Anatomy and physiology of the gastroesophageal junction. Gastroenterol Clin North Am 1997;26:467-86.

48 Penagini R, Bartesaghi B, Bianchi PA. Accuracy of the traditional pH criterion for gastro-esophageal reflux. Eur J Gastroenterol Hepatol 1992;4:813-16.

49 Washington N, Moss HA, Washington C, et al. Non-invasive detection of gastro-oesophageal reflux using an ambulatory system. Gut 1993:34:1482-6

50 Katz PO. Review article: the role of non-acid reflux in gastro-oesophageal reflux disease. Aliment Pharmacol Ther 2000;14:1539-51. 